\title{
The Effect of Chloral Hydrate upon Mitosis in Aspergillus nidulans
}

\author{
By B. MERCER AND N. R. MORRIS \\ Department of Pharmacology, College of Medicine and Dentistry of New Jersey, \\ Rutgers Medical School, Piscataway, New Jersey 08854, U.S.A.
}

(Received I3 November 1974: revised 28 December 1974)

\section{INTRODUCTION}

Although chloral hydrate has been used as an anesthetic since 1872 , its effect on cell structures and its mechanism of action are not clearly known. Early investigators (Nemec, 1904; van Regemorter, 1916; Strasburger, 1907; Sakamura, 1916) have shown that chloral hydrate produces uncoordinated chromosome movements and c-mitosis i.e. colchicine mitosis (Levan, 1938). Ris (1949) reported that chloral hydrate causes the disappearance of the mitotic spindle in grasshopper spermatocytes. Using eggs of Pleurodeles waltlii, Sentein (1974) demonstrated that chloral hydrate alters the ultrastructure of chromosomes and arrests mitosis by destroying spindle fibres. Mole-Bajer (I969) found that immediately after chloral hydrate treatment in Haemanthus katherinae, the kinetochore and continuous microtubules were absent, but microtubules soon began to re-form anew. Since most of these studies were not quantitative, the chloral hydrate effect has mainly been described qualitatively.

The simple eukaryote Aspergillus nidulans has certain advantages for the study of mitosis, the most important of which is that the genetics of the organism are well known. The cytology of mitosis in $A$. nidulans is similar to that of the higher eukaryotes in most respects (Robinow \& Caten, 1969). During mitosis, the chromosomes condense, a mitotic spindle is formed, the chromosomes undergo anaphase separation, the spindle then disappears, the chromosomes relax and two daughter nuclei are formed (Robinow \& Caten, 1969). As with many other fungi, the nuclear membrane remains intact during all phases of mitosis. A set of temperature-sensitive, conditionally lethal, mitotic mutants of $A$. nidulans has been isolated (Morris, unpublished observations). One of these mutants has been used as a tool to analyse quantitatively the effect of chloral hydrate on mitosis.

\section{METHODS}

The wild-type haploid strain of $A$. nidulans, FGSCI54 (Fungal Genetics Stock Center, Humboldt State College, Arcata, California, U.S.A.), and a temperature-sentitive ( $t s$ ) diploid derivative derived in this laboratory from FGSCI 54, $t s-706$ diploid, were used for these experiments. Aspergillus nidulans strain $t s-706$ is characterized by a reversible anaphase arrest such that mitotic spindles and condensed chromatin accumulate co-ordinately with time at temperatures above $38^{\circ} \mathrm{C}$ (Morris, unpublished). A diploid strain of $A$. nidulans $t s$-706 was constructed (Morris, unpublished) with larger, more easily identifiable spindles than the haploid. Czapek-Dox minimal medium (Difco) was supplemented with the nutritional requirements of strain I54, which were (per litre distilled water): $20 \mathrm{mg}$ adenine, $0.05 \mathrm{mg}$ biotin, $0.25 \mathrm{~g}$ methionine, $0.25 \mathrm{mg}$ choline, $0.25 \mathrm{mg}$ nicotine, $0.5 \mathrm{~g}$ sulphite and $0.5 \mathrm{~g}$ nitrite. 


\section{RESULTS AND DISCUSSION}

Strains of $A$. nidulans 154 and $t s-706$ diploid were grown in streaks on a single piece of dialysis tubing overnight at $32{ }^{\circ} \mathrm{C}$ on supplemented Czapek-Dox minimal agar medium. They were placed in liquid Czapek-Dox medium at $32{ }^{\circ} \mathrm{C}$ containing $0.02 \mathrm{M}$-chloral hydrate (Fisher, No. 7238II) and samples were removed, fixed and stained at intervals. The interphase nuclei stain very lightly with 'aceto-orcein', while the condensed chromatin of the mitotic figures stains darkly. Acid fuchsin stains the mitotic spindle, if present, and the nucleolus (Robinow \& Caten, 1969). Chloral hydrate caused the rapid disappearance of spindles such that after I $5 \mathrm{~min}$ of exposure, none of the hyphal tips contained mitotic spindles in both strain 154 and $t s-706$ diploid. In addition, chloral hydrate caused a dramatic change in the structure of the nuclei. After $20 \mathrm{~min}$ of exposure, more than $90 \%$ of the hyphal tips contained nuclei in which the chromatin was darkly stained and dispersed, as opposed to the well-defined structure of the chromatin of untreated nuclei. This phenomenon may be attributed to condensed chromosomes scattered about the hyphae as in c-mitosis (Levan, I938), or represent remnants of fragmented nuclei. With lower concentrations of chloral hydrate, these effects were observed after longer exposure times; higher concentrations of chloral hydrate produced these effects more rapidly.

Samples of strain 154 were grown overnight at $32^{\circ} \mathrm{C}$ on Czapek-Dox agar media on dialysis tubing. Four pieces of tubing were transferred for 30 min into Czapek-Dox medium with $0.02 \mathrm{M}$-chloral hydrate at $32{ }^{\circ} \mathrm{C}$, while four samples were maintained in Czapek-Dox media at $32{ }^{\circ} \mathrm{C}$ as a control. All samples were washed for $5 \mathrm{~min}$ in Czapek-Dox medium and returned to Czapek-Dox agar medium. Since there was no difference in the number or size of the colonies of the different samples, the chloral hydrate effect is reversible.

The $A$. nidulans strains $t s-706$ (diploid) and 154 (as a control) were grown overnight and maintained at a restrictive temperature of $40{ }^{\circ} \mathrm{C}$ for 90 min until $5 \mathrm{I} \cdot 5 \%$ of the hyphal tips of $t s-706$ diploid contained spindles. Each piece of dialysis tubing was divided in two such that each half contained cultures grown under identical conditions. One-half was placed in Czapek-Dox medium containing $0.02 \mathrm{M}$-chloral hydrate, at a permissive temperature of $32{ }^{\circ} \mathrm{C}$, while the other half was placed in Czapek-Dox medium at permissive temperature as a control. The percentage of hyphal tips with mitotic spindles in $t s-706$ (diploid) dropped from $5 \mathrm{I} \cdot 5$ to $10 \%$ in $\mathrm{I} \mathrm{h}$ at permissive temperature. [However, in the presence of 0.02 M-chloral hydrate, the percentage of hyphal tips with spindles dropped from $5 \mathrm{I} \cdot 5$ to $\mathrm{I} \%$ in $\mathrm{r} 5 \mathrm{~min}$ and to $0 \%$ in $\mathrm{I} \mathrm{h}$. This shows that chloral hydrate immediately causes the disappearance of accumulated mitotic spindles.

Chloral hydrate also effectively prevents the formation of mitotic spindles. Aspergillus strains 154 and $t s$-706 (diploid) were grown overnight at $32{ }^{\circ} \mathrm{C}$. These cultures were transferred to Czapek-Dox media at $38^{\circ} \mathrm{C}$ for $2 \cdot 75 \mathrm{~h}$. As described earlier, each culture was then divided in half. One-half was transferred to Czapek-Dox medium with $0.02 \mathrm{M}$-chloral hydrate at $38{ }^{\circ} \mathrm{C}$ and one-half was maintained in Czapek-Dox medium at $38^{\circ} \mathrm{C}$. While the percentage of hyphal tips with spindles increased from 25.3 to $49 \%$ in $\mathrm{I}$ h in Czapek-Dox media at $38{ }^{\circ} \mathrm{C}$, in Czapek medium at $38{ }^{\circ} \mathrm{C}$ containing chloral hydrate, the percentage of hyphal tips with spindles fell to $0.4 \%$ in $15 \mathrm{~min}$ and to $0.2 \%$ in $\mathrm{I} \mathrm{h}$. This shows that $0.02 \mathrm{M}$ chloral hydrate effectively prevents the formation of mitotic spindles, in addition to destroying those previously formed. 


\section{REFERENCES}

Levan, A. (1938). The effect of colchicine on root mitosis in Allium. Hereditas 24, 471-486.

MOle-BAJER, J. (1969). Fine structural studies of apolar mitosis. Chromosoma 26, 427-448.

NEMEC, B. (1904). Über die Einwirkung des Chloralhydrates auf Kern- und Zellteilung. Jahrbuch für wissenschaftliche Botanik 39, 645-730.

VAN ReGeMORTER, D. (19I6). Les troubles cinétiques dans les racines chloralisées. La Cellule 37, 43-73.

Ris, H. (1949). The anaphase movement of chromosomes in the spermatocytes of the grasshopper. Biological Bulletin 96, 90-106.

Robinow, C. F. \& CATEN, C. E. (1969). Mitosis in Aspergillus nidulans. Journal of Cell Science 5, 403-43I.

SAKAMURA, T. (1916). Über die Beeinflussung de Zell- und Kernteilung durch Chloralsierung mit besonderer Berücksichtigung des Verhaltens der Chromosome. Botanical Magazine (Tokyo) 30, 375-399.

Sentein, P. (1974). Action de l'hydrate de chloral sur les mitoses de segmentation de l'œuf de Pleurodele. Chromosoma 45, 21 5-244.

Strasburger, E. (I907). Über die Individualität der Chromosome und die Propfhybridenfrage. Jahrbuch fiir wissenschaftlichen Botanik 44, 482-555. 